\title{
Complete response of a metastatic gastroesophageal adenocarcinoma on irinotecan-based chemotherapy in a dialysis patient
}

This article was published in the following Dove Press journal: International Journal of Nephrology and Renovascular Disease 14 May 2010

Number of times this article has been viewed

\author{
JVerwimp' \\ F Geurs' \\ S Ponette ${ }^{2}$ \\ J Ponette ${ }^{2}$ \\ J Martens ${ }^{3}$ \\ K Bulté ${ }^{2}$ \\ 'Department of Medical Oncology, \\ ${ }^{2}$ Department of Gastroenterology, \\ ${ }^{3}$ Department of Nephrology, Regionaal \\ Ziekenhuis Sint-Maria, Ziekenhuislaan, \\ Halle, Belgium
}

\begin{abstract}
We present the first case report of a complete response of metastatic gastroesophageal cancer in a chronic hemodialysis patient with irinotecan-based chemotherapy. An elderly dialysis patient presented with diffuse liver metastases by a gastroesophageal adenocarcinoma. He received combination chemotherapy with 5 fluorouracil and irinotecan. After six months of chemotherapy, liver scans show complete remission. The principles, practice, and experience of chemotherapy with irinotecan during dialysis are discussed.
\end{abstract}

Keywords: gastroesophageal cancer, irinotecan, chemotherapy, dialysis

\section{Introduction and background}

Metastatic gastric and gastroesophageal carcinoma are known as chemotherapysensitive tumor types. Many different chemotherapy regimens were therefore developed..$^{1-3}$ However, little is known on the feasibility and efficiency of chemotherapy for these cancer types in patients with severe renal failure. ${ }^{4-6}$ Only case reports on the pharmacology of irinotecan in patients with colon or rectal cancer are available at present..$^{711}$ We present the first case of combination chemotherapy in metastatic gastroesophageal cancer in a dialysis patient.

\section{Case report}

A 73-year-old patient with a longstanding history of ischemic heart disease had been on dialysis for two years for vascular renal insufficiency. In September 2004 he was admitted for gastrointestinal blood loss. An upper gastrointestinal (GI) endoscopy showed a tumor at the gastroesophageal junction. Biopsy revealed adenocarcinoma. The computed tomography (CT) scan of the liver showed important liver metastases. CA 19.9 was very high: $24925 \mathrm{U} / \mathrm{mL}(\mathrm{nL}<37 \mathrm{U} / \mathrm{mL})$.

The patient was started on chemotherapy, the regimen consisting of L-leukovorin $250 \mathrm{mg} / \mathrm{m}^{2}$, irinotecan $50 \mathrm{mg} / \mathrm{m}^{2}$ followed by 5 -fluorouracil ( $5 \mathrm{FU}$ ) $2 \mathrm{~g} / \mathrm{m}^{2} / 24 \mathrm{~h}$, six weeks out of eight. ${ }^{12-13}$ There was neither significant nausea nor diarrhea. Dialysis was continued three times a week, (the patient was on a Monday - Wednesday - Friday schedule of dialysis) and chemotherapy was given on the Monday, just after dialysis. Only one dose was omitted owing to neutropenia. After four weeks of chemotherapy he also underwent a right carotid endarterectomy for an intercurrent transient ischemic attack in the right carotid region.

Six months after starting chemotherapy the $\mathrm{CT}$ scan of the liver showed a complete response of the numerous metastases. (Figures 1 and 2) Endoscopy showed only ondence: Filip Geurs

Department of Medical Oncology,

Ziekenhuislaan, 100, I 500 Halle, Belgium

Tel +3223636610

Fax +3223636264

Email f.geurs@regzhsintmaria.be 

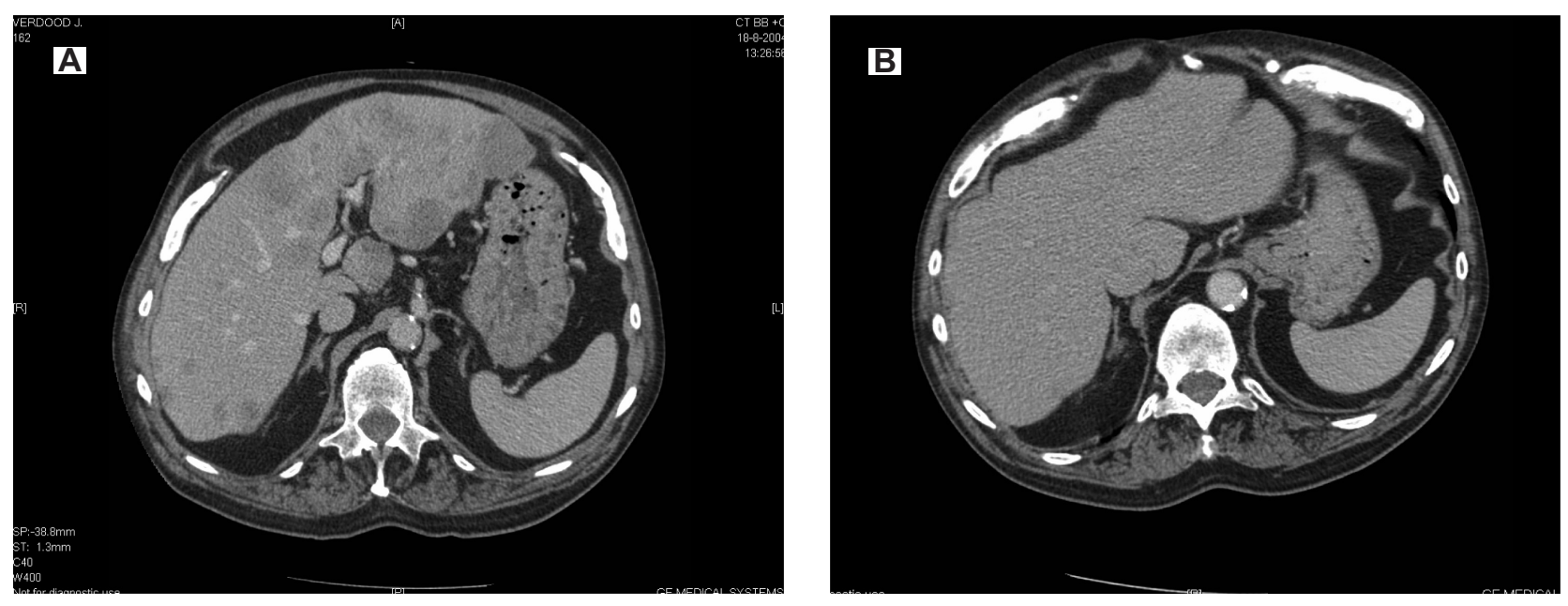

Figure I A) Initial situation with massive liver metastases in left, right, and caudate lobe of the liver. B) Complete response of diffuse liver metastases after four months of irinotecan-based chemotherapy.

minimal tumor remnants. Marker studies showed a remarkable drop in CA 19.9. (Table 1) Nine months after initiation of treatment, however, the liver metastasis and tumor marker were progressive again. Second line chemotherapy with paclitaxel was started. Doses of chemotherapy were based on a number of case reports on paclitaxel for ovarian cancer in dialysis patients. ${ }^{14,15} \mathrm{CT}$ scan after two months showed further progressive disease. The patient died in hospice 13 months after initial start of chemotherapy.

\section{Discussion}

The increase in solid tumors in a patient undergoing dialysis poses specific problems, ${ }^{16}$ especially in the choice and pharmacology of anticancer drugs, bearing in mind that all

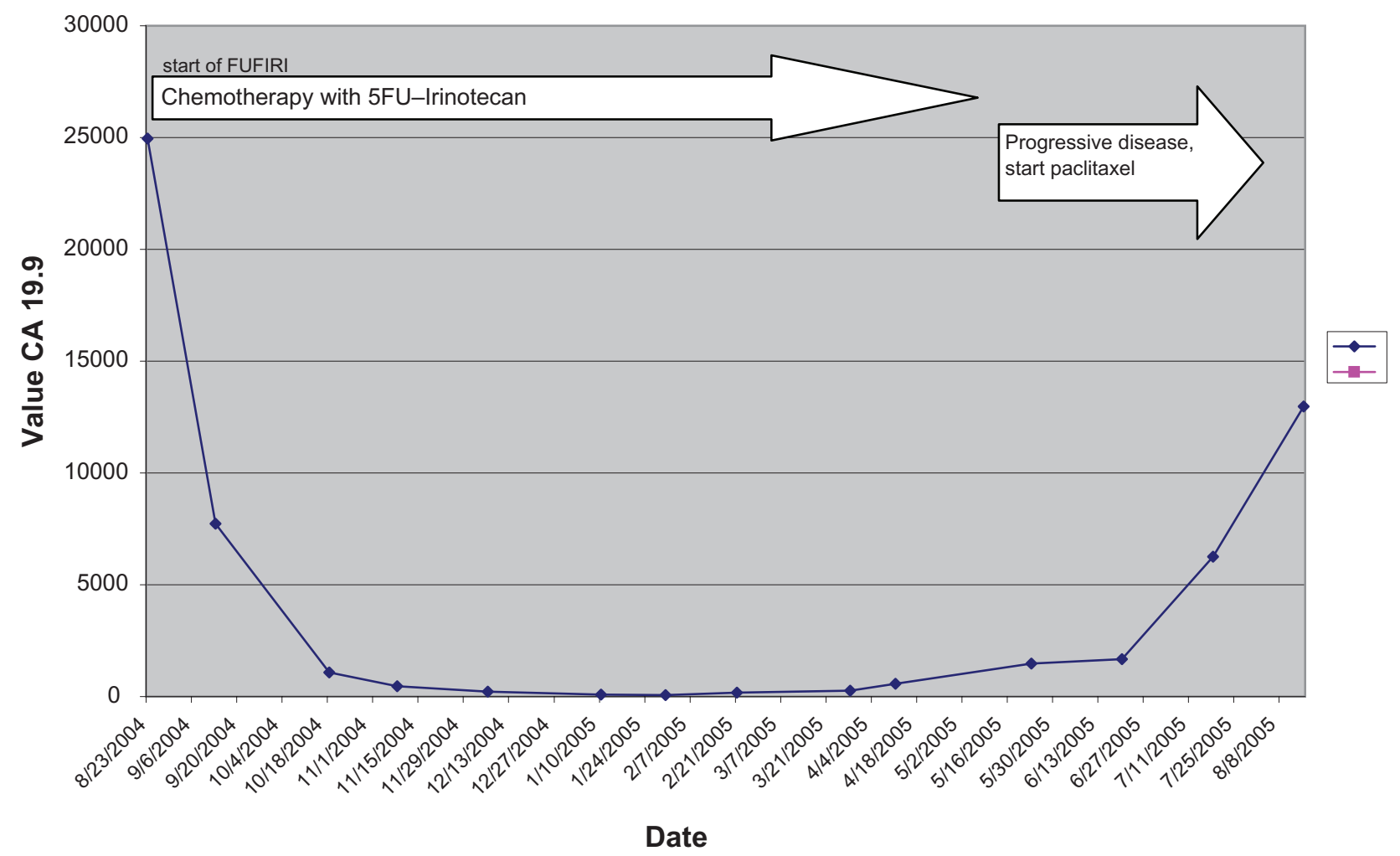

Figure 2 Evolution of CA 19.9 under chemotherapy. 
Table I Biochemistry and CA 19.9 evolution during therapy. (Normal Range LDH/lactate dehydrogenase: 200-585 U/L AP/ Alkaline Phosphatase: 38-135 U/L CA $19.9<37 \mathrm{U} / \mathrm{mL})$

\begin{tabular}{llll}
\hline DATA & LDH (U/L) & AP (U/L) & CA I9,9 (U/mL) \\
\hline $8 / 23 / 2004$ & 575 & 107 & 24952 \\
$9 / 6 / 2004$ & $50 I$ & 80 & 9861 \\
$9 / 20 / 2004$ & 427 & 79 & 3572 \\
$10 / 18 / 2004$ & 419 & 78 & 1083 \\
$11 / 1 / 2004$ & 444 & 73 & 588 \\
$11 / 15 / 2004$ & 411 & 71 & 367 \\
$11 / 29 / 2004$ & 488 & 83 & 211 \\
$12 / 13 / 2004$ & 493 & 67 & 157 \\
$12 / 27 / 2004$ & 467 & 72 & 132 \\
$1 / 10 / 2005$ & 508 & 66 & 94 \\
$1 / 24 / 2005$ & 502 & 69 & 89 \\
$2 / 7 / 2005$ & 676 & 67 & 65 \\
$2 / 21 / 2005$ & 458 & 81 & 167 \\
$3 / 7 / 2005$ & 458 & 74 & 273 \\
$4 / 4 / 2005$ & 422 & 65 & 579 \\
$4 / 18 / 2005$ & 394 & 67 & 552 \\
$5 / 2 / 2005$ & 464 & 77 & 1085 \\
$5 / 16 / 2005$ & 490 & 72 & 1483 \\
$5 / 30 / 2010$ & 561 & 73 & 1753 \\
$6 / 13 / 2005$ & 440 & 62 & 1671 \\
$6 / 27 / 2005$ & 476 & 80 & 2281 \\
$7 / 25 / 2005$ & 768 & 94 & 11181 \\
$8 / 8 / 2005$ & 139 & 69 & 12977 \\
\hline
\end{tabular}

of these drugs were developed in patients with normal liver and kidney function. For gastric cancer, 5FU has always been the backbone of treatment. ${ }^{1,2}$ In chronic hemodialysis, there are some data on dose reductions with 5FU weekly. ${ }^{17,18}$ For gastric cancer, combination chemotherapy is, however, necessary to obtain prolonged disease control and even for prolonging overall survival. ${ }^{1,2}$ Combinations of $5 \mathrm{FU}+$ cisplatin and either docetaxel or epirubicin have therefore become standard chemotherapy regimens in gastric cancer. ${ }^{19,20}$

Besides the aforementioned regimens, irinotecan-based combinations were shown to be active in first ${ }^{21}$ and second line gastric cancer. ${ }^{22}$ Its equivalence (in combination with $5 \mathrm{FU})$ in first-line metastatic gastric cancer was recently established in two studies, both comparing this regimen with a combination chemotherapy with cisplatin and 5FU. ${ }^{23,24}$

Irinotecan is metabolized in the liver to its active metabolite $\mathrm{SN}-38$, followed by biliary excretion. ${ }^{6}$ There is no significant renal elimination. The drug was evaluated in patients with serum creatinin between 1.6 and $5 \mathrm{mg} / \mathrm{dL}$ and no unexpected toxicities were seen. ${ }^{25}$ There are a number of case reports on the use of irinotecan during hemodialysis, all of which are on patients with metastatic colon cancer.

A first report mentions the use of irinotecan at a dose of $50 \mathrm{mg} / \mathrm{m}^{2}$ without significant toxicity. ${ }^{7}$ In two other case reports on dialysis patients, both patients were started with irinotecan at $50 \mathrm{mg} / \mathrm{m}^{2}$. Both reports mention that by increasing the dose, prohibitive diarrhea was the consequence. ${ }^{8,11}$

The worst outcome in higher irinotecan doses (above $125 \mathrm{mg} / \mathrm{m}^{2}$ ) was demonstrated in two other dialysis patients, where these dosages led to extreme GI toxicities and even death. $^{9}$

It can be concluded that irinotecan in terminal renal insufficiency should not be given at a dose above $50 \mathrm{mg} / \mathrm{m}^{2}$. Korean authors have made pharmacologic evaluations on the use of irinotecan in small-cell lung cancer patients during dialysis. They increased the dose up to $100 \mathrm{mg} / \mathrm{m}^{2}$ without diarrhea. They noted however that these doses were only feasible in patients of Korean descent. ${ }^{26}$

There is a very recent case report on the combination of irinotecan at a dose of $50 \mathrm{mg} / \mathrm{m}^{2}$ weekly combined with FU1600 mg/m²/24 h/week, leading to disease stabilization at six months in a dialysis patients with diffuse bone, cerebral and liver metastases of colon cancer. ${ }^{10}$

Our case report builds on this knowledge of the use of irinotecan in metastatic colorectal cancer during dialysis. This case report discusses both the weekly dose of irinotecan and the 24-hour administration of 5FU in a gastroesophageal cancer patient.

\section{Conclusion}

This is the first report on the efficacy of irinotecan- and fluorouracil-based chemotherapy in a dialysis patient with liver metastases of a gastroesophageal carcinoma. Combination chemotherapy of irinotecan and FU was extremely well tolerated, without significant delays in administration. It produced radiographically complete remission of the liver metastases, and a normalization of CA 19-9 tumor marker, leading to a remarkable overall survival.

\section{Disclosures}

The authors report no conflicts of interest in this work.

\section{References}

1. Ajani JA. Evolving chemotherapy for advanced gastric cancer. Oncologist. 2005;10(Suppl 3):49-58.

2. Gerardo R, Domenica F, Luigi M. New perspectives in the treatment of advanced or metastatic gastric cancer. World $J$ Gastroenterol. 2009;15(22):2689-2692.

3. Wood LA, Fields ALA. Chemotherapy in metastatic gastric cancer: population-based perceptions and practice patterns of medical oncologists. Br J Cancer. 2004;90:1885-1887.

4. Stemmler J, Weiser A, Hacker U, Heinemann V, Schalhorn A. Weekly irinotecan in a patient with metastatic colorectal cancer on hemodialysis due to renal failure. Onkologie. 2002;25:60-63. 
5. Kazunari T, Kazuhide H, Hirotoshi O, et al. Safety and efficacy of $\mathrm{S}-1$, a novel oral fluorouracil antitumor drug for a chronic renal failure patient maintained on hemodialysis. Oncology. 2004;66:358-364.

6. Kuhn J. Pharmacology of irinotecan. Oncology. 1998;S6:39-42.

7. Budakoglu B, Abali H, Uncu D, Yildrim N, Oksuzuglu Z, Zengin N. Good tolerance of weekly irinotecan in a patient with metastatic colorectal cancer on chronic hemodialysis. J Chemother. 2005;17(4):452-453.

8. Stemmler J, Weise A, Hacker U, Heinemann V, Schalhorn A. Weekly irinotecan in a patient with metastatic colorectal cancer on hemodialysis due to chronic renal failure. Onkologie. 2002;25(1):60-63.

9. Vénat-Bouvet L, Saint-Marcoux F, Lagarde C, Peyronnet P, Lebrun-Ly V, Tubiana-Mathieu N. Irinotecan-based chemotherapy in a metastatic colorectal cancer patient under hemodialysis for chronic renal dysfunction: two cases considered. Anticancer Drugs. 2007;18(8):977-980.

10. Schuch G. Klinische Fallstudie: systemische chemotherapie eines metastasiertes kolonkarzinoms bei eine patientin mit terminaler niereninsuffiziens. Onkologie. 2007;9-12.

11. Czock D, Rasche F, Boesler B, Shipkova M, Keller F: Irinotecan in cancer patients with ESRD. Ann Pharmacother. 2009;2:363-365.

12. Hofheinz R, Hartung G, Samel S, et al. Adding weekly irinotecan to high-dose 5-fluorouracil and folinic acid after failure for first-line HD-5-FU/FA in advanced colorectal cancer - a phase II study. Anti cancer Drugs. 2002;13:999-1004.

13. Douillard JY, Cunningham D, Roth AD, et al. Irinotecan combined with fluorouracil compared with fluorouracil alone as first-line treatment for metastatic colorectal cancer: a multicentre randomised trial. Lancet. 2000;355:1041-1047.

14. Heijns JB, van der Burg M, van Gelder T, et al. Continuous ambulatory peritoneal dialysis: pharmacokinetics and clinical outcome of paclitaxel and carboplatin treatment. Cancer Chemother Pharmacol. 2008;62:841-847.

15. Yoshida H, Sumi T, Abe K, Ishiko O. Pharmacokinetics of paclitaxel and carboplatin in a hemodialysis patient with advanced ovarian cancer. Eur J Gynaecol Oncol. 2009;30(5):583-585.

16. Vamvakas S, Bahner U, Heidland A. Increased cancer incidence in terminal kidney failure: potential pathogenetic mechanisms. Schweiz Med Wochenschr. 1997;127(14):597-604.
17. Superfin D, Iannucci AA, Davies AM. Oncologic drugs in patient with organ dysfunction: a summary. Oncologist. 2007;12:1070-1083.

18. Fleming GF, Schilsky RL, Schumm LP, et al. Phase I and pharmakinetic study of 24-hour infusion 5-fluorouracil and leucovorin in patients with organ dysfunction. Ann Oncol. 2003;14:1142-1147.

19. Van Cutsem E, Moiseyenko VM, Tjulandin S, et al. Phase III study of docetaxel and cisplatin plus fluorouracil compared with cisplatin and fluorouracil as first-line therapy for advanced gastric cancer: a report of the V325 Study Group. J Clin Oncol. 2006;24(31):4991-4997.

20. Jackson C, Cunningham D, Oliveira J. Gastric cancer: ESMO clinical recommendations for diagnosis, treatment and follow-up. Ann Oncol. 2009;4:34-36

21. Qiu L, Chen J, Zhao X, et al. A pilot study of irinotecan combined with 5-fluorouracil and leucovorin for the treatment of Chinese patients with locally advanced and metastatic gastric cancer. Tumori. 2009;95(4):432-437.

22. Catalano V, Graziano F, Santini D, et al. Second-line chemotherapy for patients with advanced gastric cancer: who may benefit? $\mathrm{Br} J$ Cancer. 2008;99(9):1402-1407.

23. Park SH, Nam E, Park J, et al. Randomized phase II study of irinotecan, leucovorin and 5-fluorouracil (ILF) versus cisplatin plus ILF (PILF) combination chemotherapy for advanced gastric cancer. Ann Oncol. 2008;9:729-733.

24. Dank M, Zaluski J, Barone C, et al. Randomized phase III study comparing irinotecan combined with 5-fluorouracil and folinic acid to cisplatin combined with 5 -fluorouracil in chemotherapy naive patients with advanced adenocarcinoma of the stomach or esophagogastric junction. Ann Oncol. 2008;19(8):1450-1457.

25. Venook AP, Enders Klein C, Fleming G, et al. A phase I and pharmacokinetic study of irinotecan in patients with hepatic or renal dysfunction or with prior pelvic radiation: CALGB 9863. Ann Oncol. 2003;14(12):1783-1790.

26. Dong MK, Hyun LK, Choon HC, and Chi YP. Successful treatment of small cell lung cancer with irinotecan in a hemodialysis patient. Korean J Int Med. 24:1:73-75.

\section{Publish your work in this journal}

The International Journal of Nephrology and Renovascular Disease is an international, peer-reviewed open-access journal focusing on the pathophysiology of the kidney and vascular supply. Epidemiology, screening, diagnosis, and treatment interventions are covered as well as basic science, biochemical and immunological studies. The journal welcomes original research, clinical studies, reviews \& evaluations, expert opinion and commentary, case reports and extended reports. The manuscript management system is completely online and includes a very quick and fair peerreview system, which is all easy to use. Visit http://www.dovepress.com/ testimonials.php to read real quotes from published authors. 